\title{
Particle Swarm Optimization Based Equivalent Circuit Estimation for On-Service Three-Phase Induction Motor Efficiency Assessment
}

\author{
Keerati Chayakulkheeree ${ }^{\mathrm{a}}$, Vichakorn Hengsritawat ${ }^{\mathrm{b}, *}$, and Petch Nantivatana \\ School of Engineering, Sripatum University, Thailand \\ E-mail: akeerati.ch@spu.ac.th, bvichchakorn.he@spu.ac.th (Corresponding author)
}

\begin{abstract}
This paper presents the particle swarm optimization based equivalent circuit estimation (PSOBECE) method for three-phase induction motor efficiency analysis, during on-service condition. The prominent point of the paper is to accurately estimate the three-phase induction motor efficiency without disturbing motor operation, using basic electrical instruments, which are clamp-on power meter and non-contact tachometer. The proposed method estimates the parameters of induction motor equivalent circuit (EC) using motor current, real power, voltage, and speed, which can be measured without interrupting the motors operations. Afterward, the motor's efficiency can be nonintrusively determined from the EC. In this paper, the 1.5, 11 and $30 \mathrm{~kW}$ motors are used for test and verify the accuracy of the proposed method. The motor efficiency test results, by shaft torque method, compliance to IEC60034 standards, are used as references to verify the accuracy of the proposed method compared to the conventional slip and current methods. The proposed method resulted in the reasonable mismatch in efficiency estimation for three-phase induction motor. The root-mean square mismatch of the proposed method, comparing to those of obtained by CM and SM, is shown to be minimum. Therefore, the proposed method could effectively and conveniently be applied for the on-service three-phase induction motor efficiency estimations.
\end{abstract}

Keywords: Three-phase induction motor efficiency estimation, three-phase induction equivalent circuit, particle swarm optimization, slip method, and current method.

ENGINEERING JOURNAL Volume 21 Issue 6

Received 28 August 2017

Accepted 16 October 2017

Published 31 October 2017

Online at http://www.engj.org/

DOI:10.4186/ej.2017.21.6.101 


\section{Introduction}

Nowadays, induction motors are widely used in industrial systems and machines, due to its simplicity and convenience. Induction motors share the high electricity used in both industrial and commercial sectors. Therefore, the efficiencies of induction motor are continuously increased to response to the energy conservation manner. It is not attractive to interrupt the motors operation and transport them to the laboratory for efficiencies determination. Therefore, in the high efficiency motor replacement program, the main difficulty of is to measure the efficiency of the existing motor without intrusion, in order to obtain the acceptable economic analysis. The reasonable method for induction motor efficiency determination during on-service condition is, then, beneficially for the economic analysis of high efficiency motor replacement program.

The accurate induction motor efficiency can be determined by standard testing in the laboratory $[1,2]$. Meanwhile, in the on-service three-phase induction motor efficiency estimation, the non-intrusion methods are commonly preferred, depending on the instrument available and degree of motor interruptible. The distinguished methods are slip method (SM), and current method (CM). The SM and CM are convenience and simple but give the low accuracy efficiency estimations [3-5]. The later methods are equivalent circuit (EC) and air gap torque (AGT) [3-9] methods. However, the AGT [6] method requires the voltage and current waveforms measurements, which require special instrument, and the stator resistance value in the analysis which may require motor interruption for data collections. As a result, many researches proposed the methods for EC parameters estimation using artificial intelligent techniques. For example, the genetic algorithm (GA) based induction motor parameters identification was proposed by Jangjit and Laohachai in [7]. The stator current, input power and power factor were investigated by the relation with the slip. However, the method was tested with only single test case without motor efficiency investigation. Meanwhile, the particle swarm optimization (PSO) based induction motor parameter identification was proposed by Picardi and Rogano in [8]. The method aimed at determination of motor parameter including stator's impedance, rotor's impedance and motor inertia. Emara, et al., proposed the modified PSO algorithm for induction motor parameter identification in [9]. In [10], Rashag, et al., used the PSO-based RBF neural network to identify the induction motor parameters. Sakthivel, et al., in [11], presented the improved PSO algorithm for induction motor parameter determination. The results on motor parameters estimation, including stator's impedance and rotor's impedance, were investigated. The mentioned previous works [7-11] indicated that the intelligent optimization techniques can be effectively used for induction motor parameter identification and the PSO algorithm was most effective for estimating the parameters over a wide operating range of the motor. In [11], the improved PSO was used to estimate the parameters of induction motor equivalent circuit. The simplified five parameters model was used to test the proposed method with two motors. Meanwhile, the efficiency determined by the obtained parameters was not investigated. Therefore, the information on induction motor parameters can be further investigated for induction motor efficiency estimation [12-13].

This paper, therefore, proposes the on-service three-phase induction motor efficiency estimation using the particle swarm optimization based equivalent circuit estimation (PSOBECE). The proposed method aimed at the reasonable estimation of motor's efficiency without interrupting its operation by using nonintrusive measurements. The measured parameters used for estimation are the motor current, real power, voltage, and speed. The proposed PSOBECE for motor efficiency estimation is verified by comparing to the laboratory test results in compliance to IEC-60034 standards with 1.5, 11 and $30 \mathrm{~kW}$ three-phase induction motors during various loading conditions. The results of the proposed PSOBECE method are compared to the conventional SM and CM.

The organization of the paper is as follows. Section 2 discusses the methods for induction motor efficiency testing and estimation. The development and test of PSOBECE method for three-phase induction motor efficiency estimation is illustrated in Section 3. The experimentation results are addressed in Section 4. Lastly, the conclusion is given.

\section{The Method for Three-Phase Induction Motor Efficiency Testing and Estimation}

The standard laboratory test and conventional on-service efficiency estimation methods for three-phase induction motor has been explored and used as references to verify the proposed method. 


\subsection{Standards of Three-Phase Induction Motor Efficiency Testing}

The admittedly efficiency test for three phases induction motors efficiency are based on IEEE-112 and IEC60034 [1-2] standards. Both standards recommend shaft-torque measurement for accurate motor efficiency determination. In the shaft-torque method, the input power can be directly measured by the power meter and the power output of the motor can be computed by

$$
P_{\text {mech }}=\frac{2 \pi N}{60} T
$$

Therefore, the motor efficiency can be accurately obtained by

$$
\text { Eff }=\frac{P_{\text {mech }}}{P_{\text {elec }}} \times 100 \%
$$

where

Eff is the efficiency of motor (\%),

$P_{\text {elec }}$ is the electrical power input to motor (W),

$P_{m e c h}$ is the mechanical power output of motor (W),

$N \quad$ is the rotor speed of motor (rpm), and

$T \quad$ is shaft torque output of motor (Nm).

\subsection{On-Service Estimations for Three-Phase Induction Motor Efficiency}

The conventional on-service three-phase induction motor efficiency estimations are usually low accuracy due to few parameters measured. In the on-service three-phase induction motor efficiency estimation, the non-intrusion methods are commonly used, depending on the instrument available and degree of motor interruptible. The conventional on-service three-phase induction motor efficiency estimations are usually low accuracy due to few parameters measured. The simple distinguished methods are slip method (SM), and current method (CM) [1-4]. The motor efficiency computed by SM and CM are shown in Eq. (3) and Eq. (4), respectively.

$$
\begin{gathered}
\text { Eff }=\frac{s_{\text {meas }}}{s_{\text {rated }}} \times \frac{P_{\text {rated }}}{P_{\text {elec }}} \times 100 \% \\
\text { Eff }=\frac{I_{\text {meas }}}{I_{\text {rated }}} \times \frac{P_{\text {rated }}}{P_{\text {elec }}} \times 100 \%
\end{gathered}
$$

where

$s_{\text {meas }}$ is the motor slip measured during operation,

$S_{\text {rated }}$ is the motor rated slip,

$P_{\text {rated }}$ is the motor rated power (W),

$I_{\text {meas }}$ is the motor current measured during operation (A), and

$I_{\text {rated }}$ is the motor rated current (A). 


\section{Development and Test of PSOBECE Method}

\subsection{Laboratory Testing for Three-Phase Induction Motor Efficiency Determination}

In this paper, the laboratory test incompliance to the standards was conducted for verifying the accuracy of proposed method, comparing to others on-site three phases motor efficiency estimation methods. The 1.5, 11 and $30 \mathrm{~kW}$ three-phase induction motors are used for investigation. The motor efficiency test by shafttorque method is illustrated in Fig. 1.

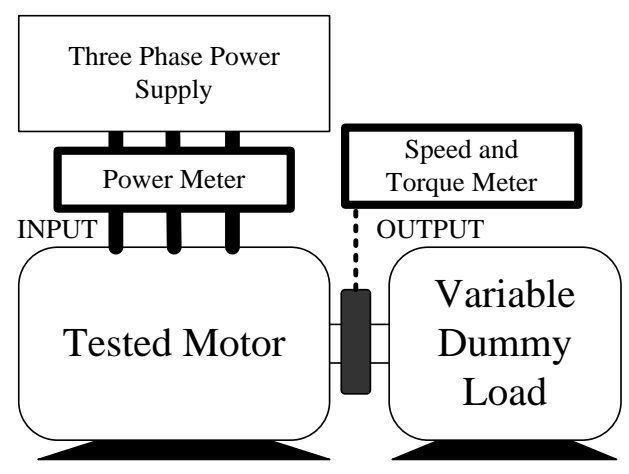

Fig. 1. Diagram of laboratory testing for three-phase induction motor efficiency determination.

The testing process based on the shaft torques method recommended by IEC60034 standards was carried out for the motors' power outputs. Then, the motors' efficiencies at the load factor of 10, 20, $30, \ldots, 100 \%$ are obtained by Eq. (1) and Eq. (2).

\subsection{PSOBECE Problem Formulation}

The motor EC addressed in Fig. 2 is used for PSOBECE method. The six parameters are estimated using PSO from the measurable variables without disturbing the motor operation, including current, voltage, real power, power factor, and slip. The six EC parameters, with slip affect, indicated in Fig. 2, are as follows [3]:

$X_{1}$ is the stator leakage reactance $(\mathrm{Ohm})$,

$R_{1}$ is the stator resistance $(\mathrm{Ohm})$,

$X_{m}$ is the magnetizing reactance $(\mathrm{Ohm})$,

$R_{c}$ is the core loss resistance (Ohm),

$X_{2}$ is the rotor leakage reactance (Ohm), and

$R_{2}$ is the rotor resistance $(\mathrm{Ohm})$.

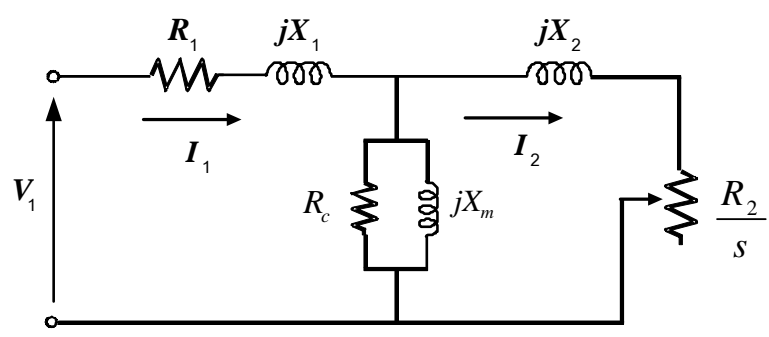

Fig. 2. The induction motor EC (where $s$ is the rotor slip). 
The set of populations in PSO [12] formulation can be expressed as,

$$
\begin{gathered}
\mathbf{P}^{\mathbf{i}(\mathbf{m})}=\left[\rho_{1}^{i(m)} \rho_{2}^{i(m)} \rho_{3}^{i(m)} \rho_{4}^{i(m)} \rho_{5}^{i(m)} \rho_{6}^{i(m)}\right]=\left[X_{1}^{i(m)} R_{1}^{i(m)} X_{2}^{i(m)} R_{2}^{i(m)} X_{m}^{i(m)} R_{c}^{i(m)}\right] \\
\mathbf{P}^{(\mathbf{m})}=\left[\mathbf{P}^{\mathbf{1}(\mathbf{m})} \mathbf{P}^{\mathbf{2}(\mathbf{m})} \ldots \mathbf{P}^{\mathbf{N}(\mathbf{m})}\right]^{T}
\end{gathered}
$$

where

$\mathbf{P}^{\mathbf{i}(\mathbf{m})}$ is the sub-matrix of the particle $\mathrm{i}$ in the $\mathrm{m}$-th iteration, and

$\mathbf{P}^{(\mathbf{m})}$ is the matrix of all particles in the m-th iteration.

The objective function is to minimize the evaluation value $(E V)$ as,

$$
E V=\left(\frac{I_{\text {cal }}}{I_{\text {meas }}}-1\right)^{2}+\left(\frac{P_{\text {cal }}}{P_{\text {meas }}}-1\right)^{2}+\left(\frac{P F_{\text {cal }}}{P F_{\text {meas }}}-1\right)^{2}
$$

where

$I_{\text {cal }}, I_{\text {meas }}$ are the motor current obtained by analyzing the EC and by actual measurement, respectively, $P_{c a l}, P_{\text {meas }}$ are the motor real power obtained by analyzing the EC and by actual measurement, respectively, and

$P F_{c a l}, P F_{\text {meas }}$ are the motor power factor obtained by analyzing the EC and by actual measurement, respectively.

Thereafter, the PSO algorithm [12] is used to solve the minimization problem. The PSOBECE computational procedure can be illustrated as follows:

Step1: Obtain measurement value of $I_{\text {meas }}, P_{\text {meas }}, P F_{\text {meas }}$,

Step 2: Initialize $\mathbf{P}^{(\boldsymbol{0})}=\left[\mathbf{P}^{\mathbf{1}(\mathbf{0})} \mathbf{P}^{\mathbf{2}(\mathbf{0})} \ldots \mathbf{P}^{\mathbf{N}(\mathbf{0})}\right]^{T}$, randomly,

Step 3: Set $m=0, \mathbf{v}^{\mathbf{i}(0)}=[0]_{1 \times 6}$, for all $i$,

Step 4: Compute $I_{c a l}^{i(m)}, P_{c a l}^{i(m)}, P F_{c a l}^{i(m)}$ of $\mathbf{P}^{\mathbf{i}(\mathbf{m})}$, for all $i$,

Step 5: Compute $E V^{i(m)}$, for all $i$,

Step 6: Obtain the personal best (pbesti(m)) which are $\mathbf{P}^{\mathbf{i}(\mathbf{m})}$ that provide the minimum $E V$ of the particle $i$ and global best $\left(\boldsymbol{g b e s t}^{(\boldsymbol{m})}\right)$ which is $\mathbf{P}^{\mathbf{i}(\mathbf{m})}$ that provide the minimum $E V$ among all particle in swarm,

Step 7: If the $E V^{i(m)}$ computed by gbest $^{(m)}$ is less than 0.001 or $\mathrm{m}=100$, go to Step 11,

Step 8: Compute the velocity as,

$$
\begin{aligned}
\mathbf{v}^{\mathbf{i}(m)} & =\left[v_{1}^{i(m)} v_{2}^{i(m)} v_{3}^{i(m)} v_{4}^{i(m)} v_{5}^{i(m)} v_{6}^{i(m)}\right], \\
v_{j}^{i(m)} & =w \cdot v_{j}^{i(m-1)}+C_{1} \cdot \text { rand }_{1} \cdot\left(\text { pbest }_{j}^{i(m)}-\rho_{j}^{i(m)}\right)+C_{2} \cdot \operatorname{rand}_{2} \cdot\left(\text { gbest }_{j}^{(m)}-\rho_{j}^{i(m)}\right),
\end{aligned}
$$

Step 9: Update the particle by $\mathbf{P}^{\mathbf{i}(\mathbf{m}+\mathbf{1})}=\mathbf{P}^{\mathbf{i}(\mathbf{m})}+\mathbf{v}^{i(m)}$,

Step 10: $m=m+1$, go to Step 4,

Step 11: Stop.

where $w$ is the weighting factor; $C_{1}, C_{2}$ are the constants acceleration factors, whereas, rand ${ }_{1}$ and rand $_{2}$ are uniform random numbers. In this research $C_{1}, C_{2}$ and $w$ used are 1 , and the number of particle, $\mathrm{N}$ in Eq. (6), is 1000 .

The EC parameters as indicated in Fig. 2 are the output of the computational procedure. As a results, the motor air-gap power $\left(P_{a g}\right)$ can be obtained by 


$$
P_{a g}=I_{2}^{2}\left(\frac{R_{2}}{s}\right)
$$

Then, the motor's efficiency at the measured condition can be determined by

$$
E f f=\frac{\left(P_{a g}-P_{m s l o s s}\right)}{P_{\text {elec }}} \times 100 \%
$$

where $P_{m s l o s s}$ is the motor mechanical plus stray loss $(\mathrm{kW})$. In this paper, the values of motor mechanical plus stray loss recommended by [1] are used.

\section{Experimentation Results}

The 1.5, 11 and $30 \mathrm{~kW}$ three-phase induction motors have been tested by the method presented in Section 3.1. The motor's efficiencies at the load factor of $10,20,30, \ldots, 100 \%$, are obtained by the shaft-torque method and used for reference. The efficiencies estimated by SM, CM, and the proposed PSOBECE methods of all tested motor, are shown in Fig. 3 to Fig. 5 respectively. The example of the experimentation results of the proposed method with 100 PSO runs for $80 \%$ loading of the $30 \mathrm{~kW}$ tested motor are shown in Fig. 6.

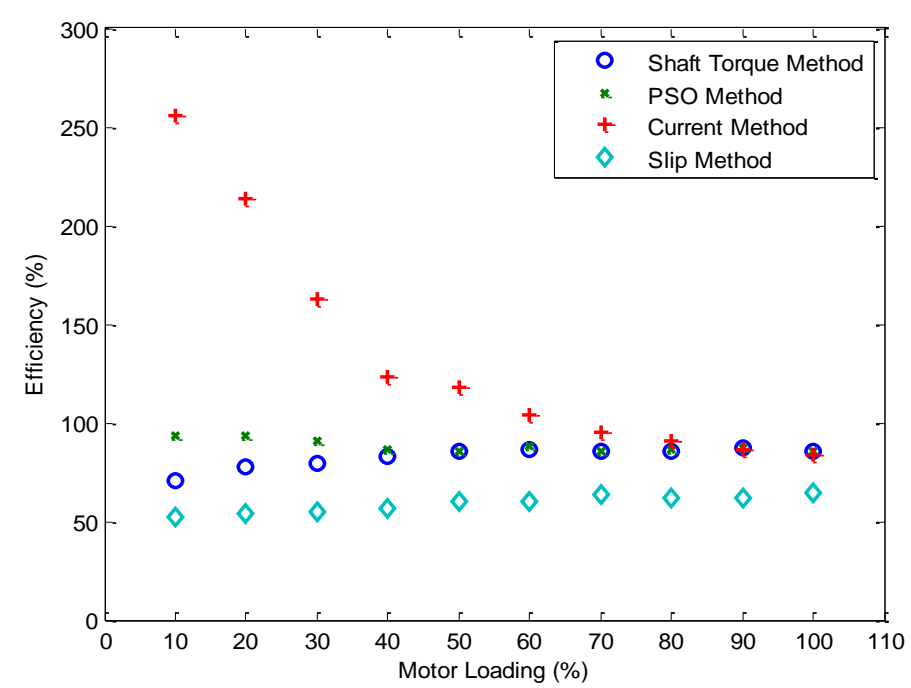

Fig. 3. The efficiencies of the investigated motors obtained by shaft torque, SM, CM, and PSOBECE methods for the $1.5 \mathrm{~kW}$ tested motor. 


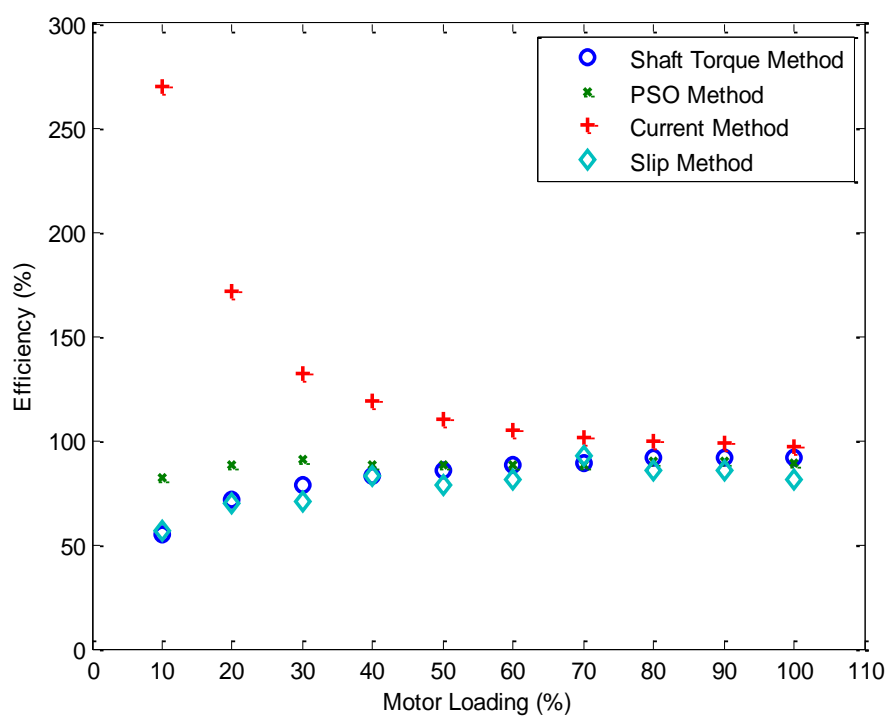

Fig. 4. The efficiencies of the investigated motors obtained by shaft torque, SM, CM, and PSOBECE methods for the $11 \mathrm{~kW}$ tested motor.

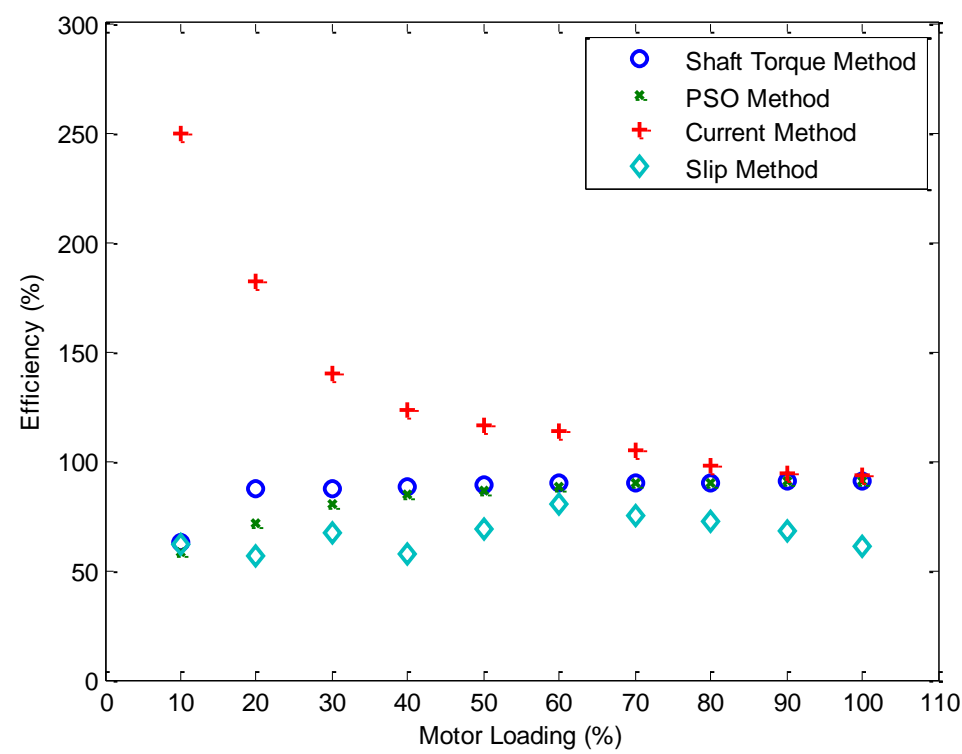

Fig. 5. The efficiencies of the investigated motors obtained by shaft torque, SM, CM, and PSOBECE methods for the $30 \mathrm{~kW}$ tested motor. 


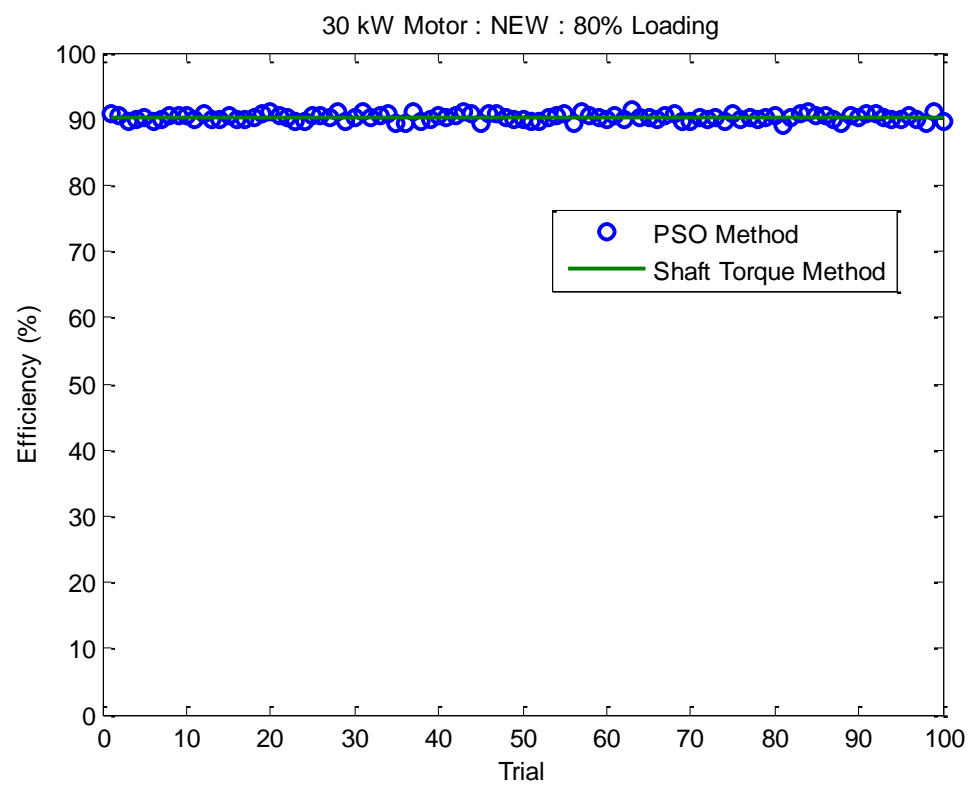

Fig. 6. One hundred trials of efficiencies estimated by the proposed PSOBECE method for the $30 \mathrm{~kW}$ tested motor

The results shown that the CM provides better efficiency estimation than those of SM for the loading $50 \%$ of motor rated power and higher. Contrariwise, the SM results in higher accuracies induction motor efficiencies estimations than those of $\mathrm{CM}$ at the motor loading lower than $50 \%$ of motor rated power. Meanwhile, The proposed PSOBECE method for induction motor efficiency estimation results in the minimum root mean square error mismatch to shaft-torque method for the estimation of induction motor operated at $50 \%$ of rated power and above as shown in Table 1 to Table 3.

Table 1. The overall root means square mismatch to shaft torque method of CM, SM, and PSOBECE for $1.5 \mathrm{~kW}$ tested motor.

\begin{tabular}{|c|c|c|c|c|c|c|c|c|c|}
\hline Load & Input & Output & $\begin{array}{c}\text { Test } \\
\text { Efficiency }\end{array}$ & \multicolumn{2}{|c|}{ Current Method } & \multicolumn{2}{|c|}{ Slip Method } & \multicolumn{2}{|c|}{$\begin{array}{l}\text { PSO Method } \\
\text { (Proposed) }\end{array}$} \\
\hline \multirow{2}{*}{$(\%)$} & \multirow{2}{*}{$(\mathrm{kW})$} & \multirow{2}{*}{$(\mathrm{kW})$} & \multirow{2}{*}{$(\%)$} & Eff. & Error & Eff. & Error & Eff. & Error \\
\hline & & & & $(\%)$ & (\%point) & $(\%)$ & (\%point) & $(\%)$ & (\%point) \\
\hline 10.0 & 0.33 & 0.23 & 71.00 & 255.35 & 184.35 & 51.95 & 19.05 & 93.69 & 22.69 \\
\hline 20.0 & 0.40 & & 78.00 & 213.97 & 135.97 & 53.57 & 24.43 & 93.31 & 15.31 \\
\hline 30.0 & 0.55 & 0.44 & 79.20 & 162.83 & 83.63 & 54.55 & 24.65 & 90.64 & 11.44 \\
\hline 40.0 & 0.80 & 0.67 & 83.20 & 123.53 & 40.33 & 56.25 & 26.95 & 86.61 & 3.41 \\
\hline 50.0 & 0.85 & & 85.50 & 117.82 & 32.32 & 60.50 & 25.00 & 85.36 & 0.14 \\
\hline 60.0 & 1.07 & 0.92 & 86.30 & 103.90 & 17.60 & 60.08 & 26.22 & 88.16 & 1.86 \\
\hline 70.0 & 1.25 & 1.07 & 85.80 & 95.29 & 9.49 & 63.43 & 22.37 & 85.50 & 0.30 \\
\hline 80.0 & 1.39 & 1.19 & 85.80 & 91.09 & 5.29 & 61.66 & 24.14 & 86.53 & 0.73 \\
\hline 90.0 & 1.59 & 1.39 & 87.10 & 86.57 & 0.53 & 61.99 & 25.11 & 87.04 & 0.06 \\
\hline 100.0 & 1.77 & 1.52 & 85.60 & 84.00 & 1.60 & 64.16 & 21.44 & 85.33 & 0.27 \\
\hline \multirow{3}{*}{\multicolumn{5}{|c|}{$\begin{aligned} \text { Root Mean Square Error (Total) } & = \\
\text { Root Mean Square Error }(<50 \% \text { Load) } & = \\
\text { Root Mean Square Error }(\geq 50 \% \text { Load)) } & =\end{aligned}$}} & 25.01 & & 7.60 & & 2.99 \\
\hline & & & & & 61.79 & & 11.97 & & 7.47 \\
\hline & & & & & 6.40 & & 9.84 & & 0.34 \\
\hline
\end{tabular}


Table 2. The overall root means square mismatch to shaft torque method of CM, SM, and PSOBECE for $11 \mathrm{~kW}$ tested motor.

\begin{tabular}{|c|c|c|c|c|c|c|c|c|c|}
\hline Load & Input & Output & $\begin{array}{c}\text { Test } \\
\text { Efficiency }\end{array}$ & \multicolumn{2}{|c|}{ Current Method } & \multicolumn{2}{|c|}{ Slip Method } & \multicolumn{2}{|c|}{$\begin{array}{l}\text { PSO Method } \\
\text { (Proposed) }\end{array}$} \\
\hline \multirow{2}{*}{$(\%)$} & \multirow{2}{*}{$(\mathrm{kW})$} & \multirow{2}{*}{$(\mathrm{kW})$} & \multirow{2}{*}{$(\%)$} & Eff. & Error & Eff. & Error & Eff. & Error \\
\hline & & & & $(\%)$ & (\%point) & $(\%)$ & (\%point) & $(\%)$ & (\%point) \\
\hline 10.0 & 1.98 & 1.10 & 55.27 & 286.42 & 231.15 & 33.33 & 21.94 & 82.78 & 27.51 \\
\hline 20.0 & 3.18 & 2.19 & 68.76 & 181.41 & 112.65 & 48.43 & 20.33 & 90.00 & 21.24 \\
\hline 30.0 & 4.15 & 3.28 & 78.84 & 144.90 & 66.06 & 53.01 & 25.83 & 91.22 & 12.38 \\
\hline 40.0 & 5.63 & 4.66 & 82.85 & 117.23 & 34.38 & 54.71 & 28.14 & 90.53 & 7.68 \\
\hline 50.0 & 6.36 & 5.44 & 85.46 & 112.23 & 26.77 & 55.35 & 30.11 & 90.29 & 4.83 \\
\hline 60.0 & 7.58 & 6.51 & 85.81 & 101.91 & 16.10 & 58.05 & 27.76 & 87.21 & 1.40 \\
\hline 70.0 & 8.64 & 7.42 & 85.80 & 98.46 & 12.66 & 61.11 & 24.69 & 87.59 & 1.79 \\
\hline 80.0 & 10.76 & 9.24 & 85.93 & 91.78 & 5.85 & 67.47 & 18.46 & 87.39 & 1.46 \\
\hline 90.0 & 11.42 & 9.80 & 85.83 & 92.04 & 6.21 & 71.28 & 14.55 & 87.06 & 1.23 \\
\hline 100.0 & 12.85 & 11.00 & 85.60 & 89.03 & 3.43 & 68.48 & 17.12 & 88.48 & 2.88 \\
\hline \multirow{3}{*}{\multicolumn{5}{|c|}{$\begin{aligned} \text { Root Mean Square Error (Total) } & = \\
\text { Root Mean Square Error }(<50 \% \text { Load }) & = \\
\text { Root Mean Square Error }(\geq 50 \% \text { Load })) & =\end{aligned}$}} & 27.00 & & 7.41 & & 3.82 \\
\hline & & & & & 66.93 & & 12.13 & & 9.42 \\
\hline & & & & & 5.82 & & 9.33 & & 1.06 \\
\hline
\end{tabular}

Table 3. The overall root means square mismatch to shaft torque method of CM, SM, and PSOBECE for $30 \mathrm{~kW}$ tested motor.

\begin{tabular}{|c|c|c|c|c|c|c|c|c|c|}
\hline Load & Input & Output & $\begin{array}{c}\text { Test } \\
\text { Efficiency }\end{array}$ & \multicolumn{2}{|c|}{ Current Method } & \multicolumn{2}{|c|}{ Slip Method } & \multicolumn{2}{|c|}{$\begin{array}{l}\text { PSO Method } \\
\text { (Proposed) }\end{array}$} \\
\hline \multirow{2}{*}{$(\%)$} & \multirow{2}{*}{$(\mathrm{kW})$} & \multirow{2}{*}{$(\mathrm{kW})$} & \multirow{2}{*}{$(\%)$} & Eff. & Error & Eff. & Error & Eff. & Error \\
\hline & & & & $(\%)$ & (\%point) & $(\%)$ & (\%point) & $(\%)$ & (\%point) \\
\hline 10.0 & 4.87 & 3.07 & 63.13 & 249.96 & 186.83 & 61.66 & 1.47 & 58.51 & 4.62 \\
\hline 20.0 & 7.12 & 6.18 & 86.87 & 182.11 & 95.24 & 56.19 & 30.68 & 71.09 & 15.78 \\
\hline 30.0 & 10.44 & 9.09 & 87.11 & 140.09 & 52.98 & 67.05 & 20.06 & 80.10 & 7.01 \\
\hline 40.0 & 13.90 & 12.21 & 87.83 & 123.68 & 35.85 & 57.54 & 30.29 & 84.51 & 3.32 \\
\hline 50.0 & 16.04 & 14.34 & 89.37 & 116.53 & 27.16 & 68.56 & 20.81 & 86.84 & 2.53 \\
\hline 60.0 & 18.63 & 16.79 & 90.10 & 113.30 & 23.20 & 80.52 & 9.58 & 88.16 & 1.94 \\
\hline 70.0 & 23.89 & 21.56 & 90.27 & 104.52 & 14.25 & 75.36 & 14.91 & 89.74 & 0.53 \\
\hline 80.0 & 26.13 & 23.56 & 90.18 & 97.81 & 7.63 & 72.72 & 17.46 & 89.53 & 0.65 \\
\hline 90.0 & 29.31 & 26.49 & 90.38 & 93.95 & 3.57 & 68.24 & 22.14 & 90.45 & 0.07 \\
\hline 100.0 & 32.67 & 29.59 & 90.56 & 93.13 & 2.57 & 61.21 & 29.35 & 91.04 & 0.48 \\
\hline \multirow{3}{*}{\multicolumn{5}{|c|}{$\begin{aligned} \text { Root Mean Square Error (Total) } & = \\
\text { Root Mean Square Error }(<50 \% \text { Load }) & = \\
\text { Root Mean Square Error }(\geq 50 \% \text { Load })) & =\end{aligned}$}} & 22.28 & & 6.83 & & 1.85 \\
\hline & & & & & 54.81 & & 11.89 & & 4.55 \\
\hline & & & & & 6.58 & & 8.17 & & 0.56 \\
\hline
\end{tabular}

Moreover, the proposed PSOBECE method provides the lowest root mean square error for the estimation of induction motor operated at below $50 \%$ of rated power comparing to those of estimated by $\mathrm{CM}$ and SM. The overall root mean square error, for the estimation of induction motors operated at $10 \%-$ $100 \%$ of rated power loading, of the proposed PSOBECE method are $2.99 \%(1.5 \mathrm{~kW}), 3.82 \%(11 \mathrm{~kW})$ and $1.85 \%(30 \mathrm{~kW})$ mismatch to shaft-torque method, which are the lowermost to CM and SM.

\section{Conclusion}

This paper proposed the PSOBECE method for the on-service three-phase induction motor efficiency estimation. The proposed method was authenticated by comparing to the standard laboratory efficiency test 
and conventional CM and SM methods. The experimentation shown that the proposed PSOBECE method resulted in the fair accuracy in the three-phase induction motor efficiency estimation, without intrusion of motor operation. The root-mean square error of the proposed PSOBECE method is shown to be the lowest comparing to $\mathrm{CM}$ and SM methods. Therefore, the proposed method could effectively and conveniently be applied for the on-service three-phase induction motor efficiency estimation.

\section{Acknowledgement}

This research was granted by the joint program funding of Electricity Generating Authority of Thailand (EGAT) and Thailand Research Fund (TRF) under contract number RDG57D0004.

\section{References}

[1] IEEE Standard Test Procedure for Polyphase Induction Motors and Generators, IEEE Standard 112-2004, Nov. 2004.

[2] International Standard, Rotating Electrical Macbines, IEC60034, 1999.

[3] J. S. Hsu, J. D. Kueck, M. Olszewski, D. A. Casada, P. J. Otaduy, and L. M. Tolbert, "Comparison of induction motor field efficiency evaluation methods," IEEE Transaction on Industry Application, vol. 34, no. 1, pp. 117-125, Jan./Feb. 1998.

[4] B. Lu, T. G. Habetler, and R. G. Harley, "A survey of efficiency-estimation methods for in-service induction motors," IEEE Transaction on Industry Application, vol. 42, no. 4, pp. 924-932, Jul./ Aug. 2006.

[5] U.S. Department of Energy, "Determining electric motor load and efficiency," Motor Challenge, DOE/GO-10097-517.

[6] J. S. Hsu and B. P. Scoggins, "Field test of motor efficiency and load changes through air-gap torque," IEEE Transaction on Energy Conversion, vol. 10, no. 3, pp. 471-477, Sept. 1995.

[7] S. Jangjit and P. Laohachai, "Parameter estimation of three-phase induction motor by using genetic algorithm," Journal of Electrical Engineering \& Technology, vol. 4, no. 3, pp. 360-364, 2009.

[8] C. Picardi and N. Rogano, "Parameter identification of induction motor based on particle swarm optimization," in Proceeding of IEEE Power Electronic, Electrical Drives, Automation and Motion International Symposium (SPEEDAM), May 2006, pp. 968-973.

[9] J. R. Holmquist, J. A. Rooks, and M. E. Richter, "Practical approach for determining motor efficiency in the field using calculated and measured values," IEEE Transaction on Industrial Application, vol. 40, no. 1, pp. 242-248, Jan/Feb, 2004.

[10] H. M. Emara, W. Elshamy, and A. Bahgat, "Parameter identification of induction motor using modified Particle Swarm Optimization algorithm," in Proceeding of IEEE Industrial Electronics International Symposium (ISIE), June 2008, pp. 841-847.

[11] V. P. Sakthivel, R. Bhuvanneswari, and S. Subramanian, "An improved particle swarm optimization for induction motor parameter determination," International Journal of Computer Application, vol. 1, no. 2, pp. 62-67, 2010.

[12] A. I. Canakoglu, A. G. Yetgin, H. temurtas, and M. Turan, "Induction motor parameter estimation using metaheuristic methods," Turkish Journal of Electrical Engineering \& Computer Sciences, vol. 22, pp. 1177-1192, 2014.

[13] C. Kral and A. Haumer, "Consistent equivalent circuit parameters of induction motors for the calculation of partial load efficiencies," in IEEE International Symposium on Industrial Electronics, Cambridge, UK, 30 June-2 July 2008, pp. 698-705. 